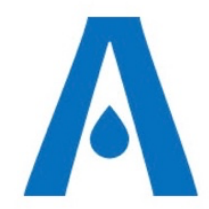

The IJA is a peer-reviewed open-access, electronic journal, freely available without charge to users

Produced by the AquacultureHub non-profit Foundation Sale of IJA papers is strictly forbidden

\title{
Shewanella algae: an emerging causative agent for ulcer disease in freshwater-farmed American eel Anguilla rostrata
}

\author{
Huicong Wang1, Ying Gu2,3, Jun Chen', Haipeng Cao1,2,3*
}

${ }^{1}$ Department of Animal Husbandry \& Veterinary Medicine, Jiangsu Vocational College of Agriculture and Forestry, Jurong Jiangsu 212400, P.R. China.

2 National Pathogen Collection Center for Aquatic Animals, Shanghai Engineering Research Center of Aquaculture, Shanghai Ocean University, Shanghai 201306, P.R. China.

${ }^{3}$ Key Laboratory of Freshwater Fishery Germplasm Resources, Ministry of Agriculture of P. R. China, Shanghai 201306, P.R. China.

Key words: Ulcer disease; Anguilla rostrata; Shewanella algae; Antibiotic susceptibility.

\begin{abstract}
Ulcer disease has resulted in substantial economic losses in eel aquaculture. Yet only scarce information is available on Shewanella algae as a possible causal agent for this disease. In this study, a virulent strain, temporarily named MY, was isolated from diseased American eel, Anguilla rostrata, suffering from ulcer disease and was identified as $S$. algae through molecular and phenotypic methods. A phylogenetic tree was constructed to examine MY and compare it to other known isolates. Besides, isolate MY has exhibited susceptibility to aminoglycosides and sulfonamides drugs for veterinary uses in aquaculture, as revealed when screened against a range of conventional antibiotics. To the best of our knowledge, this is the first report of ulcer disease caused by $S$. algae in American eel.
\end{abstract}

The first two authors contributed equally to this work.

* Corresponding author. Tel.: +862161900453, fax: +862161900452, e-mail: hpcao@shou.edu.cn 


\section{Introduction}

American eel Anguilla rostrata is widely cultivated in many countries such as America, Canada, China, Greenland and Guyana (Chen et al., 2005; Kwak et al., 2019). Especially in China, with the rapid development of farming techniques, $A$. rostrata has been cultured successfully in freshwater (Lin et al., 2006) and has become one of the most important commercial fish species which has brought a high profit in recent years (Xu et al., 2012). Its production has increased to over 89,000 tons in 2017 (Ministry of Agriculture and Rural Affairs of China, 2018; Ye et al., 2019). However, under intensive culture, this industry has been severely affected by bacterial diseases (Guo et al., 2010; Xu et al., 2017). Thus, more attention should be paid to bacteriosis to enable further development of this industry.

Ulcer disease is one of the most important infectious bacterial diseases in eel aquaculture (Yang et al., 2015). So far, several bacterial pathogens such as Aeromonas hydrophila, Edwardsiella tarda, and Vibrio vulnificus have been reported to cause this disease (Zheng et al., 1999; Zheng et al., 2005; Lei et al., 2012; Xu et al., 2017). Shewanella algae is a Gram-negative, rod-shaped, motile bacterium, which is widely distributed in freshwater and marine environments (Srinivas et al., 2015; Torri et al., 2018; Tseng et al., 2018), and it has emerged as an aquaculture pathogen, which differs from Shewanella putrefaciens in its ability to produce $\beta$-haemolysis (Khashe et al., 1998; Holt et al., 2005; Lee et al., 2019). The occurrence of $S$. algae infections is most commonly found in warm waters with a temperature of $30^{\circ} \mathrm{C}, \mathrm{pH} 7$ and salinity of $30 \mathrm{ppt}$ (Holt et al., 2005; Han et al., 2017; Tseng et al., 2018). However, little information is available on Shewanella algae as a causal agent for ulcer disease in American eel.

This study aims to characterize the phenotype, taxonomic position and antibiotic susceptibility of this strain. As far as we know, this is the first report of $S$. algae as a pathogen of ulcer disease in American eel.

\section{Materials and methods}

American eel samples

Twenty-one-year-old diseased freshwater-cultured American eel averaging $100.3 \pm 1.5 \mathrm{~g}$ suffering from ulcer disease were sampled from an eel farm in Fujian China during May 2018. The farm had 1000 square meters of ponds with American eel stocked at an initial rearing density of 550 juveniles per square meter. The water quality during the disease outbreak was $7.57 \mathrm{pH}, 0.08 \mathrm{mg} \mathrm{L}-1$ total ammonia, $0.05 \mathrm{mg} \mathrm{L}-1$ nitrite and $7.21 \mathrm{mg} \mathrm{L}-1$ dissolved oxygen. Diseased samples were placed in sterile bags, kept in ice and transported to the laboratory, according to Cao et al. (2016). 
Isolation of Bacteria

Each sampled diseased eel was externally disinfected with 75\% alcohol and dissected, according to Yang et al. (2017). Before conducting a careful examination of parasites and viruses using traditional methods as described by Huang et al. (2010) and Deng et al. (2009), a section of $0.1 \mathrm{~g}$ of ulcerative muscle and liver sample of each eel was cut and streaked onto nutrient agar (NA) plates (Sinopharm Chemical Reagent Co., Ltd.). After incubation for $24 \mathrm{~h}$ at $28^{\circ} \mathrm{C}$, the dominant uniform isolates were purified by streaking and re-streaking onto NA plates. Pure isolates of the dominant colonies were stored at $-80^{\circ} \mathrm{C}$ supplemented with $15 \%$ glycerol, as recommended by $\mathrm{Ma}$ et al. (2018). A representative of the predominant isolates, temporarily named MY, was characterized further in the present study.

\section{Identification of the pathogen}

\section{Molecular identification}

The extraction of genomic DNA from the MY isolate, as well as PCR amplification and sequencing of its $16 \mathrm{~S}$ rRNA gene, were performed according to Li et al. (2015). The nearly complete 16S rRNA gene sequence was assembled using MegAlign, Editseq and Seqman software. A search was performed in the National Centre for Biotechnology Information (NCBI) database for sequence homology using the Basic Local Alignment Search Tool (BLAST) program. A phylogenetic tree from the nearly complete $16 \mathrm{~S}$ rRNA gene sequence of the isolate and its homologous sequences was constructed using the neighbor-joining method.

\section{Phenotypic identification}

The isolate MY was identified phenotypically by API 20E system recommended by Santos et al. (1993), where the isolate MY was grown on NA plates at $280 \mathrm{C}$ for $24 \mathrm{~h}$, and the bacterial suspension was then used to inoculate the Analytical Profile Index (API 20E) test strips (Biomerieux, France) following the manufacturer's instruction. The plate was incubated at $37^{\circ} \mathrm{C}$ and observed after $18 \mathrm{~h}$ for checking against the API identification index and database. Information related to $S$. algae previously reported ( $\mathrm{Li}$ et al., 2015; Cao et al., 2018) serves as a reference.

\section{Bacterial virulence assay}

The experiment was conducted in strict accordance with the Regulations on Experimental Animals Administration of China (Publication No. 676). It was approved by the Institutional Animal Ethics Committee of Shanghai Ocean University with permission No. SHOU-DW-2019-034. Bacterial virulence was examined by experimentally infecting healthy freshwater cultured American eel.

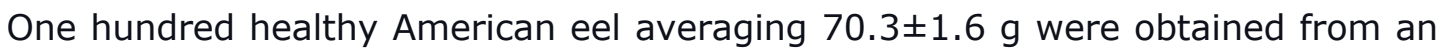
eel farm in Guangdong China. The experimental fish were acclimated in ten replicate aquaria (ten fish per aquarium) supplied with $100 \mathrm{~L}$ of aerated filtered farming water at $28^{\circ} \mathrm{C}$ for 14 days. Before the bacterial virulence assay, the isolate MY was inoculated onto the NA plate, incubated at $28^{\circ} \mathrm{C}$ for $24 \mathrm{~h}$, then washed with normal saline into a sterile tube. Its cell density was determined by counting 
colony-forming units after a ten-fold serial dilution in sterile distilled water, as described by Han et al. (2018). Two replicates of ten healthy fish were challenged by intramuscular injection (Chen et al., 2015) with $0.1 \mathrm{~mL}$ of the isolate MY at a concentration of $2.0 \times 104 \mathrm{CFU} \mathrm{mL}-1$ to $2.0 \times 107 \mathrm{CFU} \mathrm{mL}-1$. Another two replicates of ten healthy fish exposed to the same experimental conditions and injected intramuscularly $0.1 \mathrm{~mL}$ of normal saline remained unchallenged and served as control. The experimental fish were kept at 280C and observed daily for seven days without feeding and water change. Any dead fish were immediately removed and sampled to re-isolate and confirm if the challenge isolate explicitly caused the mortality, according to Han et al. (2017). Briefly, the livers of the dead fish were sampled on NA plates to re-isolate the challenge isolate, which was identified phenotypically and molecularly, as described above. The mean lethal dose (LD50) value is calculated using the linear regression method, as recommended by Spielmann et al. (1999).

\section{Antibiotic sensitivity assay}

The antibiotic sensitivity of isolate MY was assayed on NA plates using the KirbyBauer disk diffusion method, as recommended by Cen et al. (2019). Twenty-one antibiotic discs were acquired from Hangzhou Binhe Microorganism Reagent Co., Ltd. The zones of inhibition were measured after a $24 \mathrm{~h}$ incubation period at $28^{\circ} \mathrm{C}$. The antibiotic susceptibility was determined according to the manufacturer's guidelines.

\section{Results}

Identification of the pathogenic isolate

Only a pathogenic isolate, temporarily named MY, was isolated from diseased freshwater-farmed American eel and identified by molecular and phenotypic methods as S. algae. Its near-complete 16S rRNA gene sequence (1400 nucleotides) was submitted to the GenBank database with the accession no. MN795538. The similarity of $99 \%$ to $100 \%$ is observed in the $16 \mathrm{~S}$ rRNA gene sequence between the MY isolate and other $S$. algae isolates from the GenBank database. The phylogenetic tree confirms that isolate MY is identified with $S$. algae strain (Figure 1). Also, isolate MY was confirmed by the phenotypic features as $S$. algae (Table 1 ) with $100 \%$ identity compared to the reference strain. No parasites and viruses were detected in the diseased American eel from which isolate MY was isolated. 


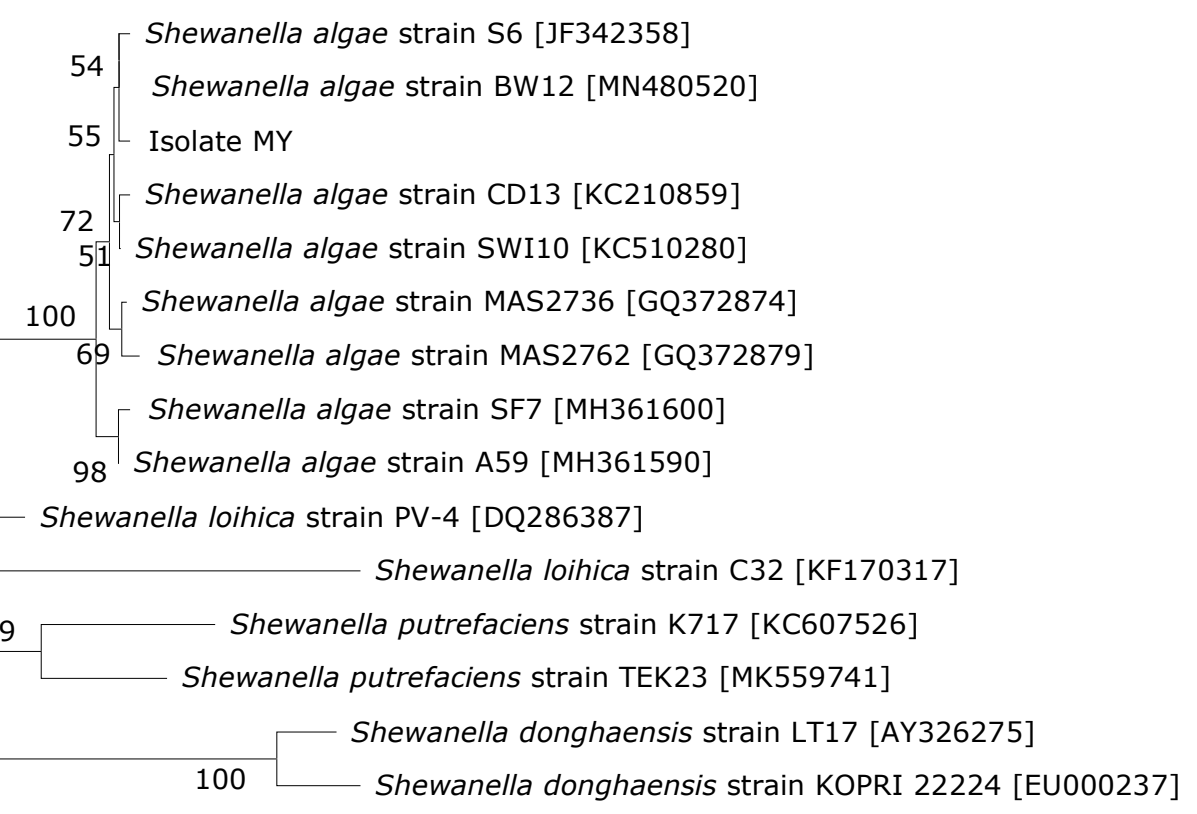

0.005

Fig. 1. A 16S rRNA gene tree of 14 known bacteria and the MY isolate constructed using the neighbor-joining method. The bootstrap values (\%) are shown besides the clades, accession numbers are indicated beside the names of strains, and scale bars represent distance values. 
Table 1. Phenotypic characterization of isolate MY.

\begin{tabular}{|c|c|c|}
\hline \multirow{2}{*}{ Tests } & \multicolumn{2}{|c|}{ Reaction } \\
\hline & Isolate MY & S. algae \\
\hline Arginine dihydrolase & $\mathrm{R}^{+}$ & $\mathrm{R}^{+}$ \\
\hline Cytochrome oxidase & $\mathrm{R}^{+}$ & $\mathrm{R}^{+}$ \\
\hline$\beta$-Galactosidase & $\mathrm{R}^{-}$ & $\mathrm{R}^{-}$ \\
\hline Gelatinase & $\mathrm{R}^{+}$ & $\mathrm{R}^{+}$ \\
\hline Lysine decarboxylase & $\mathrm{R}^{-}$ & $\mathrm{R}^{-}$ \\
\hline Ornithine decarboxylase & $\mathrm{R}^{+}$ & $\mathrm{R}^{+}$ \\
\hline Tryptophan deaminase & $\mathrm{R}^{-}$ & $\mathrm{R}^{-}$ \\
\hline Urease & $\mathrm{R}^{+}$ & $\mathrm{R}^{+}$ \\
\hline Citrate utilization & $\mathrm{R}^{+}$ & $\mathrm{R}^{+}$ \\
\hline Acetoin production & $\mathrm{R}^{-}$ & $\mathrm{R}^{-}$ \\
\hline Indole production & $\mathrm{R}^{-}$ & $\mathrm{R}^{-}$ \\
\hline $\mathrm{H}_{2} \mathrm{~S}$ production & $\mathrm{R}^{+}$ & $\mathrm{R}^{+}$ \\
\hline Arabinose fermentation & $\mathrm{R}^{-}$ & $\mathrm{R}^{-}$ \\
\hline Amygdalin fermentation & $\mathrm{R}^{-}$ & $\mathrm{R}^{-}$ \\
\hline Glucose fermentation & $\mathrm{R}^{+}$ & $\mathrm{R}^{+}$ \\
\hline Inositol fermentation & $\mathrm{R}^{-}$ & $\mathrm{R}^{-}$ \\
\hline Mannitol fermentation & $\mathrm{R}^{-}$ & $\mathrm{R}^{-}$ \\
\hline Melibiose fermentation & $\mathrm{R}^{-}$ & $\mathrm{R}^{-}$ \\
\hline Rhamnose fermentation & $\mathrm{R}^{-}$ & $\mathrm{R}^{-}$ \\
\hline Sucrose fermentation & $\mathrm{R}^{-}$ & $\mathrm{R}^{-}$ \\
\hline Sorbitol fermentation & $\mathrm{R}^{-}$ & $\mathrm{R}^{-}$ \\
\hline
\end{tabular}

$\mathrm{R}^{+}$: positive reaction; $\mathrm{R}^{-}$: negative reaction.

aThe reference strain's data are in accordance with those previously reported (Li et al., 2015; Cao et al., 2018).

Isolate MY is found to be pathogenic in an experimental challenge. The death of the experimental fish was increased gradually over time after the challenge. 15\%$100 \%$ of the experimental fish challenged with isolate MY died at an LD50 value of $4.42 \times 105$ CFU mL-1 (Table 2) and exhibited rot and necrosis of muscles, similar to that seen in the originally diseased American eel (Figure 2). Also, the re-isolated bacteria from the experimentally dead fish are identified phenotypically and molecularly as isolate MY. No clinical signs or mortality are noted in the control of the American eel. 
Table 2. Cumulative mortality of experimental American eel infected by isolate MY.

\begin{tabular}{|c|c|c|c|c|c|c|c|c|c|c|c|}
\hline \multirow[t]{2}{*}{ Group } & \multirow{2}{*}{ 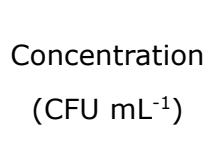 } & \multirow{2}{*}{$\begin{array}{c}\text { Fish } \\
\text { no. }\end{array}$} & \multicolumn{7}{|c|}{$\begin{array}{l}\text { Dead fish no. on day after } \\
\text { challenge }\end{array}$} & \multirow{2}{*}{$\begin{array}{c}\text { Average } \\
\text { cumulative } \\
\text { mortality (\%) }\end{array}$} & \multirow{2}{*}{ 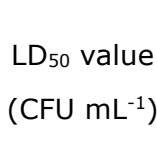 } \\
\hline & & & 1 & 2 & 3 & 4 & 5 & 6 & 7 & & \\
\hline \multirow{2}{*}{ Control } & \multirow{2}{*}{0} & 10 & 0 & 0 & 0 & 0 & 0 & 0 & 0 & \multirow{2}{*}{0} & \multirow{10}{*}{$4.42 \times 10^{5}$} \\
\hline & & 10 & 0 & 0 & 0 & 0 & 0 & 0 & 0 & & \\
\hline \multirow{2}{*}{ Treatment 1} & \multirow{2}{*}{$2.0 \times 10^{4}$} & 10 & 0 & 0 & 1 & 1 & 0 & 0 & 0 & \multirow{2}{*}{15} & \\
\hline & & 10 & 0 & 0 & 0 & 1 & 0 & 0 & 0 & & \\
\hline \multirow{2}{*}{ Treatment 2} & \multirow{2}{*}{$2.0 \times 10^{5}$} & 10 & 0 & 1 & 1 & 1 & 0 & 0 & 0 & \multirow{2}{*}{30} & \\
\hline & & 10 & 1 & 1 & 0 & 1 & 0 & 0 & 0 & & \\
\hline \multirow{2}{*}{ Treatment 3} & \multirow{2}{*}{$2.0 \times 10^{6}$} & 10 & 2 & 2 & 1 & 1 & 1 & 0 & 0 & \multirow{2}{*}{75} & \\
\hline & & 10 & 2 & 1 & 2 & 2 & 1 & 0 & 0 & & \\
\hline \multirow{2}{*}{ Treatment 4} & \multirow{2}{*}{$2.0 \times 10^{7}$} & 10 & 4 & 3 & 2 & 1 & 0 & 0 & 0 & \multirow{2}{*}{100} & \\
\hline & & 10 & 5 & 3 & 2 & 0 & 0 & 0 & 0 & & \\
\hline
\end{tabular}

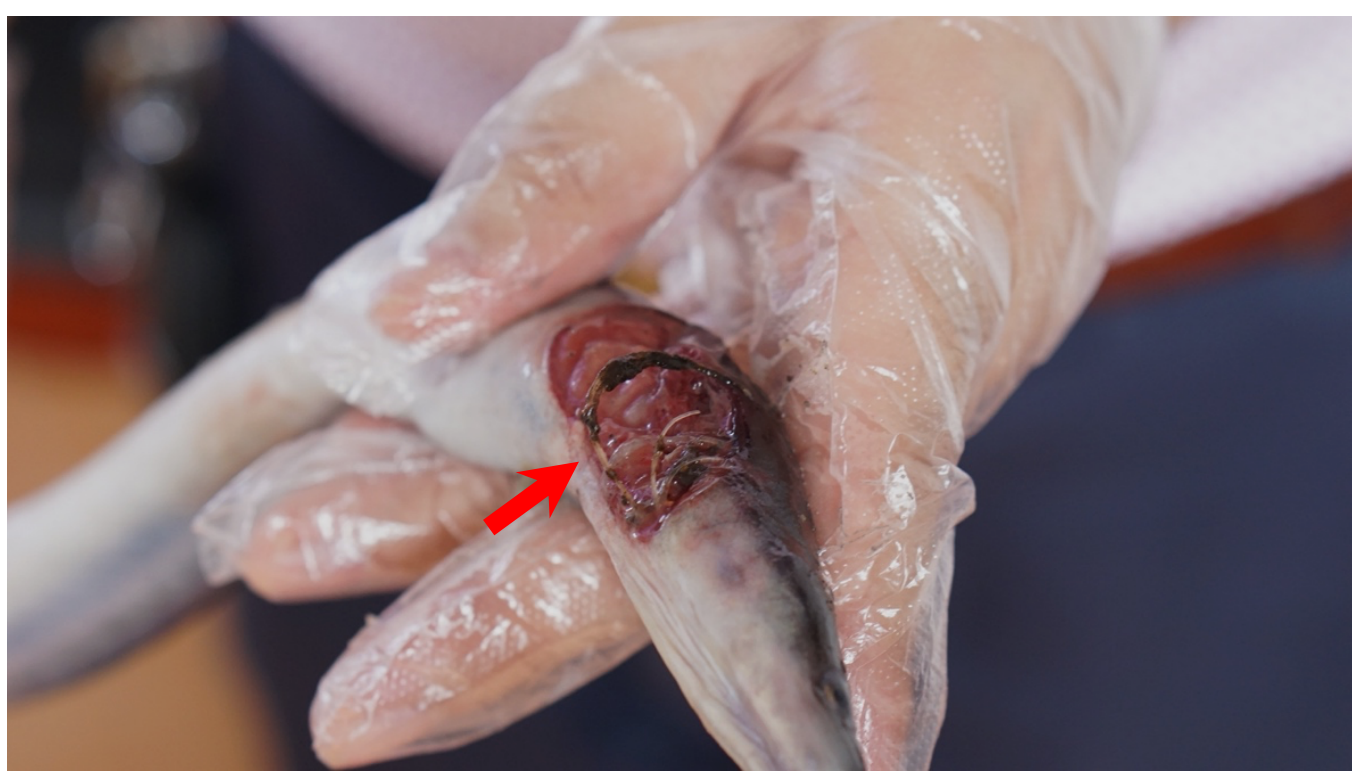

Fig. 2. Pathological symptoms of the freshwater-cultured American eel suffering from ulcer disease. Arrow shows the rotten and necrotic muscle.

\section{Antibiotic sensitivity}

The antibiotic sensitivity of isolate MY is shown in Table 3. The data indicate that isolate MY is sensitive to ciprofloxacin, cotrimoxazole, enrofloxacin, erythromycin, florfenicol, furazolidone, gentamycin, neomycin, netilmicin, norfloxacin, ofloxacin, polymyxin B, streptomycin, sulfamethoxydiazine, and intermediately sensitive to lincomycin, and resistant to ampicillin, azithromycin, ceftazidime, doxycycline, rifampicin, tetracycline. Therefore, we suggest that isolate MY did not develop resistance to aminoglycosides and sulfonamides drugs used in eel aquaculture. 
Table 3. Susceptibility of isolate MY to antibiotics.

\begin{tabular}{|c|c|c|}
\hline Antibiotics & $\begin{array}{l}\text { Content } \\
(\mu \mathrm{g} / \mathrm{disc})\end{array}$ & Inhibition zone diameter $(\mathrm{mm})$ \\
\hline Ampicillin & 10 & $8.05 \pm 0.07^{R}$ \\
\hline Azithromycin & 10 & $8.75 \pm 0.35^{R}$ \\
\hline Ceftazidime & 30 & $11 \pm 0^{\mathrm{R}}$ \\
\hline Ciprofloxacin & 5 & $26.1 \pm 0.57^{s}$ \\
\hline Cotrimoxazole* & $23.75 / 1.25$ & $23.5 \pm 1.41^{\mathrm{s}}$ \\
\hline Doxycycline* & 30 & $11.1 \pm 0.57^{\mathrm{R}}$ \\
\hline Enrofloxacin & 5 & $27.15 \pm 0.21^{\mathrm{s}}$ \\
\hline Erythromycin & 15 & $28.15 \pm 0.21^{\mathrm{s}}$ \\
\hline Florfenicol* $^{*}$ & 30 & $35.55 \pm 0.64^{\mathrm{s}}$ \\
\hline Furazolidone & 30 & $19 \pm 0^{\mathrm{s}}$ \\
\hline Gentamycin & 10 & $22.85 \pm 0.21^{\mathrm{S}}$ \\
\hline Lincomycin & 2 & $10.1 \pm 0.14^{\mathrm{I}}$ \\
\hline Neomycin* & 30 & $26.65 \pm 0.50^{S}$ \\
\hline Netilmicin & 30 & $27.25 \pm 0.35^{\mathrm{s}}$ \\
\hline Norfloxacin & 10 & $22.1 \pm 0.14^{\mathrm{S}}$ \\
\hline Ofloxacin & 5 & $25.75 \pm 0.35^{\mathrm{S}}$ \\
\hline Polymyxin B & 30 & $12 \pm 0^{\mathrm{s}}$ \\
\hline Rifampicin & 5 & $6.5 \pm 0.71^{R}$ \\
\hline Streptomycin & 10 & $26.5 \pm 0.71^{\mathrm{s}}$ \\
\hline Sulfamethoxydiazine* & 5 & $16.5 \pm 0.71^{\mathrm{s}}$ \\
\hline Tetracycline & 30 & $9.25 \pm 0.35^{R}$ \\
\hline
\end{tabular}

Data are presented as the mean \pm standard deviation.

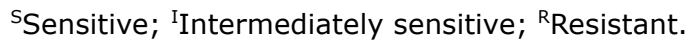

*Antibiotics for eel aquaculture use (Ministry of Agriculture of China, 2013).

\section{Discussion}

The association of $S$. algae in aquaculture has been well documented with massive mortality reported in Scinenops ocellata (Chen et al., 2003), Haliotis diversicolor (Cai et al., 2006; Huang et al., 2018), Babylonia (Li., 2015), Cynoglossus semilaevis (Han et al., 2017), Penaeus vannamei (Cao et al., 2018) and Lates calcarifer (Erfanmanesh et al., 2019). However, there is limited information on S. algae isolates as causal agents for ulcer disease in freshwater-cultured eel. In the present work, an S. algae pathogen was isolated from American eel suffering from ulcer disease in Fujian China during May 2018, and its phenotype, taxonomic position, and antibiotic susceptibility were characterized. To our knowledge, this is the first report of an $S$. algae pathogen as a causative agent for ulcer disease in freshwater-farmed American eel.

Ulcer disease is usually induced in fish with bacterial pathogens and their virulence factors such as adhesion ability, cytotoxin secretion, enzymatic activity, hemolytic activity, invasiveness (Sakata et al., 1988; Liu et al., 2005; Zhang et 
al., 2010; Wang et al., 2012; Xu et al., 2014). S. algae is a well-recognized pathogen with virulence factors, including adhesion ability, cytotoxin secretion, enzymatic activity, and hemolytic activity (Lee et al., 2019; Chelsey et al., 2019). Ulcer disease caused by $S$. algae is probably associated with the production of these virulent factors. In the present study, the MY isolate was found to cause mortality in healthy $A$. rostrata with an LD50 value of $4.42 \times 105 \mathrm{CFU} \mathrm{mL}-1$. This phenomenon further demonstrates the potential threat of $S$. algae to freshwater farming of American eel. Apart from the virulence of the MY isolate, there might be other secondary factors that induce ulcer diseases in the American eel, such as reduced health status, misuse of contaminated feed and lack of adequate water disinfection (Lin et al., 2006); these should also be raised as concerns.

Antibiotic resistance in $S$. algae has been reported in aquaculture as a result of the wide use of antibiotics (Cao et al., 2018; Wu et al., 2019). In our study, the MY isolate developed resistance to doxycycline. The same resistance has also been observed in the pathogenic $S$. algae isolated from diseased $P$. vannamei and $L$. calcarifer (Cao et al., 2018; Erfanmanesh et al., 2019). The MY isolate in our study has exhibited sensitivity to aminoglycosides and sulfonamides drugs used in the eel farming regions, suggesting that the outbreak of this disease may not have resulted from the abuse of antibiotics.

In conclusion, the present study, for the first time, reports $S$. algae isolate as a causal agent for ulcer disease in $A$. rostrata. The pathogenicity of the MY isolate supports this infection as an emerging threat in American eel farming.

\section{Acknowledgments}

This work has been financially supported by the Earmarked Fund for Fishery SciTech Innovation \& Popularization Project of Jiangsu Province (No. Y2018-8) and the Sci-Tech Innovation Team Fund of Jiangsu Vocational College of Agriculture and Forestry (No. 110751269).

\section{References}

Cai J., Chen H., Thompson K.D., Li C., 2006. Isolation and identification of Shewanella alga and its pathogenic effects on post-larvae of abalone Haliotis diversicolor supertexta. Journal of Fish Diseases, 29(8): 505-508.

Cao H., Chen S., Lu L., An J., 2018. Shewanella algae: an emerging pathogen of black spot disease in freshwater-cultured whiteleg shrimp (Penaeus vannamei). Israeli Journal of Aquaculture - Bamidgeh, 70: 1472.

Cao H., Long X., Lu L., Yang X., Chen B., 2016. Citrobacter freundii: a causative agent for tail rot disease in freshwater cultured Japanese eel Anguilla japonica. Israeli Journal of Aquaculture - Bamidgeh, 68: 1271.

Cen K., Qiu C., Xu L., Bao W., Chen Q., Wu S., 2019. Screening of heterogeneous strains and its effect on antimicrobial susceptibility tests based on K-B method. Chinese Journal of Microecology, 31(4):466-470.

Chelsey A.B., Pandit R.T., Hilary A.B., 2019. Shewanella algae keratitis. Indian Journal of Ophthalmology, 67(1): 148-150. 
Chen C., Hu C., Chen X., Zhang L., 2003. Identification and characterization of Shewanella algae as a novel pathogen of ulcer disease of fish Scinenops ocellata. Oceanologia et Limnologia Sinica, 34(1): 1-8.

Chen J., Xu X., Guo S., 2015. Pathological changes of American eel (Anguilla rostrata) infected by Aeromonas hydrophila. Journal of Jimei University (Natural Science), 20(3): 161-166.

Chen X., 2005. Techniques of seed rearing of Auguilla rostrata. Shandong Fisheries, 22(6): 31-33.

Deng G., Xie J., Li S., Bai J., Chen K., Ma D., Jiang X., Lao H., 2009. Isolation and preliminary identification of the pathogen from largemouth bass ulcerative syndrome. Journal of Fisheries of China, 33(5): 871-877.

Erfanmanesh A., Beikzadeh B., Mohseni F.A., Nikaein D., Mohajerfar T., 2019. Ulcerative dermatitis in barramundi due to coinfection with Streptococcus iniae and Shewanella algae. Diseases of Aquatic Organisms, 134(2): 89-97.

Guo S., Guan R., Feng J., Chen C., 2010. Influences of blood and biochemical parameters on American eels (Anguilla rostrata) Challenged by Aeromonas hydrophila. Journal of Jimei University (Natural Science), 15(2): 93-97.

Han Z., Sun J., Lv A., Sung Y., Shi H., Hu X., Xing K., 2017. Isolation, identification and characterization of Shewanella algae from reared tongue sole, Cynoglossus semilaevis Günther. Aquaculture, 468: 356-362.

Han Z., Sun J., Lv A., Sun X., Shi H., Hu X., Wang Q., Guo Y., Xing K., Wang A., 2018. Changes in intestinal microflora of Cynoglossus semilaevis Günther following Shewanella algae infection. International Journal of Agriculture and Biology, 20(4): 933-938.

Holt H.M., Gahrn-Hansen B., Bruun B., 2005. Shewanella algae and Shewanella putrefaciens: Clinical and microbiological characteristics. Clinical Microbiology and Infection, 11(5):347-352.

Huang Y., Cheng J., Chen S., Hong Y., 2018. Draft genome sequence of carbapenem-resistant Shewanella algae strain AC isolated from small abalone (Haliotis diversicolor). Journal of Global Antimicrobial Resistance, 14: 65-67.

Huang Y., Li X., Wu X., Pang Y., Huang G., Wei X., Tong G., 2010. Detection and diagnosis procedure for fish parasitic diseases. Fisheries Science \& Technology Information, 37(2): 83-85.

Khashe S., Janda J.M., 1998. Biochemical and pathogenic properties of Shewanella alga and Shewanella putrefaciens. Journal of Clinical Microbiology, 36(3): 783-787.

Kwak T.J., Engman A.C., Lilyestrom C.G., 2019. Ecology and conservation of the American eel in the Caribbean region. Fisheries Management and Ecology, 26(1): 42-52.

Lee Y., Tung K., Cheng J., 2019. Genomic characterization of carbapenemresistant Shewanella algae isolated from Asian hard clam (Meretrix lusoria). Aquaculture, 500: 300-304.

Lei Y., Xiao Y., 2012. Identification and antibiotic sensitivity experiment of Aeromonas hydrophila isolated from skin ulcer of artificial breeding Anguilla anguilla. Journal of Fujian Fisheries, 34(3): 183-188. 
Lin M., Liao G., 2006. Comparison of Anguilla anguilla and Anguilla rostrata in biological characteristics and farming techniques. China Fisheries, 1: 24-26.

Li S., Zhang J., Qiu D., Yang S., Huang Z., 2015. Biological characteristics and pathogenicities of Shewanella algae and Shewanella abalone from Babylonia. Agricultural Science \& Technology, 16(9): 1845-1850.

Liu M., Han Y., 2005. Isolation and identification of Aeromonas sobria from infected carps and its sensitivity to drugs. Journal of Northeast Agricultural University, 36(4): 486-489.

Ma J., Yang N., Chen Y., Jiang F., Huang H., 2018. First isolation and identification of Shewanella xiamenensis from diseased Nile tilapia (Oreochromis niloticus L.). Agricultural Biotechnology, 7(1): 74-78.

Ministry of Agriculture of China, 2013. The First Catalogue of Veterinary Prescription Drugs. China Animal Health, 15(11): 81-83.

Ministry of Agriculture and Rural Affairs of China, 2018. China Fishery Statistical Yearbook. China Agriculture Press, Beijing. 25 pp.

Sakata T., Hattori M., 1988. Characteristics of Vibrio vulnificus from diseased tilapia. Fish Pathology, 23(1): 33-44.

Santos Y., Romalde J. L., Bandin I., Magarinos B., Nunez S., BarjaA J. L., Toranzo A. E., 1993. Usefulness of the API-20E system for the identification of bacterial fish pathogens. Aquaculture, 116(2-3): 111-120.

Spielmann H., Genschow E., Liebsch M., Halle W., 1999. Determination of the starting dose for acute oral toxicity $\left(L_{50}\right)$ testing in the up and down procedure (UDP) from cytotoxicity data. Alternatives to Laboratory Animals, 27: 957-966.

Srinivas J., Pillai M., Vinod V., Dinesh K.R., 2015. Skin and soft tissue infections due to Shewanella algae - an emerging pathogen. Journal of Clinical and Diagnostic Research, 9(2): 16-20.

Torri A., Bertini S., Schiavone P., Congestrì F., Matteucci M., Sparacino M., Testa G., Pedna M.F., Sambri V., 2018. Shewanella algae infection in Italy: report of 3 years' evaluation along the coast of the northern Adriatic Sea. New Microbes and New Infections, 23: 39-43.

Tseng S., Liu P., Lee Y., WuZ., Huang C., Cheng C., Tung K., 2018. The pathogenicity of Shewanella algae and ability to tolerate a wide range of temperatures and salinities. Canadian Journal of Infectious Diseases and Medical Microbiology, 2018: 6976897.

Wang X., Geng X., Li X., Dong X., Sun J., 2012. Isolation and identification of skin ulcer epidemics pathogens from groupers Epinephelus coioides. Journal of Tianjin Agricultural University, 19(3): 19-25.

Wu Z., Huang Y., Chao W., 2019. Reversal of carbapenem-resistance in Shewanella algae by CRISPR/Cas9 genome editing. Journal of Advanced Research, 18: 61-69.

Xu X., Chen J., Feng J., Guo S., 2017. Pathological and ultrastructural changes of American eel (Anguilla rostrata) infected by Edwardsiella tarda. Journal of Jimei University (Natural Science), 22(6): 17-23. 
Xu J., Geng Y., Wang K., Chen C., Zhou Y., Chen D., Huang X., Pu Y., 2014. Isolation, identification and pathogenicity of Aeromonas sobria from Triplophysa siluroides. Sichuan Journal of Zoology, 33(5): 708-714.

Xu J., Guan R., Chen X., Lai X., 2012. Studies on fingerlings breeding of Anguilla japonica and Anguilla rastrata by recirculating aquaculture system. Fishery Modernization, 39(3): 23-27, 45.

Yang H., Zhao Y., 2015. Ulcer disease in aquatic animals. Current Fisheries, 40(10): 90-92.

Yang Y., Guo C., Cao H., Lu L., Yang X., 2017. Shewanella putrefaciens: an emerging pathogen for farmed yellow catfish Pelteobagrus fulvidraco. Israeli Journal of Aquaculture - Bamidgeh, 69: 1425.

Ye H., Zhong C., Chi B., 2019. Analysis on the development of eel industry in Fujian. China Fisheries, 4: 56-61.

Zhang X., Bing X., Yao D., Zhu M., Qin G., 2010. Ulcer disease and biological and molecular characterization of pathogenic Aeromonas sobria isolated from oriental weatherfish Misgurnus anguillicaudatus. Fisheries Science, 29(12):696702.

Zheng F., Shi C., Pan H., Wu S., 2005. Isolation and identification of pathogen from diseased Anguilla anguilla. Journal of Shanghai Fisheries University, 14(3): 3242-3247.

Zheng G., Zhou K., 1999. Drug resistance of Aeromonas hydrophila strains isolated from skin ulcer of Anguilla anguilla. Journal of Fishery Sciences of China, 6(3): 70-73. 